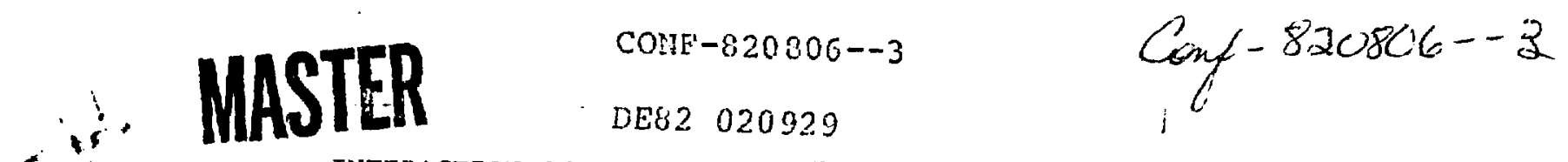

INTERACTION OF NOBLE-METAL FISSION PRODUCIS WITH PYROLYTIC SILICON CARBIDE

R. J. Lauf and U. N. Braski

Metals and Ceramics Division, Oak Ridge National Laboratory, P.C. Box X, Oak Ridge, Tennessee 37330

Fuel particles for the High-Temperature Gas-Cooled Reactor (HTGR) contain layers of pyrolytic carbon and silicon carbide, which act as a miniature pressure vesse $i$ and form the primary fission product barrier. Of the many fission products formed during irradiation, the noble metals are of particular interest because they interact significantly with the SiC layer and their concentrations are somewhat higher in the low-enriched uranium fuels currently under consideration. To study fission product-SiC interactions, particles of $\mathrm{UO}_{2}$ or $\mathrm{UC}_{2}$ are doped with fisision product elements before coating and are then held in a thermal gradient up to several thousand hours. 1 Examination of the SiC coatings by TEM-AEM after annealing shows that silver behaves differently from the paljadium group.

\title{
Palladium Group
}

Figure 1 shows the typical SiC microstructure as deposited at $1500^{\circ} \mathrm{C}$ and $0.70 \mathrm{~m} / \mathrm{min}$. The SiC coating from a $\mathrm{UC}_{2}-\mathrm{Mo}-\mathrm{Ru}-\mathrm{Rh}-\mathrm{Pd}$ particle is shown in Fig. 2 after annealing $260 \mathrm{~h}$ at $1597^{\circ} \mathrm{C}$ in a thermal gradient of $275^{\circ} \mathrm{C} / \mathrm{cm}$. Small $(\leqslant 1 \mu \mathrm{m})$ nodules of a noble metal compound occur along SiC grain boundaries. No significant restructuring of the SiC behind the nodules is evident, suggesting that they move by dissolving $\mathrm{SiC}$ at the leading edge and by forming $\mathrm{SiC}$ at the trailing edge. Analysis of the nodules by EDX indicated $\mathrm{Pd}, \mathrm{Rh}, \mathrm{U}$, and $\mathrm{Si}$, which is consistent with electron microprobe results, except that prior observations could not differentiate $P d$ and $R h$ because of overlapping $L \boldsymbol{x}$ lines. Our analysis with the JEM-100CX resolved $\mathrm{Pd}$ and $\mathrm{Rh} K \alpha$ lines. A few larger nodules observed in this specimen had a more equiaxed shape and appeared to contain only $U$ and Si. Migration of $U$ is seen only in carbide-based fuel particles.

\section{Silver}

In concentrations typical of end-of-life fuel, silver neither attacks the SiC layer nor forms second phases as does the Pd group. However, silver is sometimes released from particles even when the SiC layer is intact. 2 Figure 3 shows the microstructure of the $\mathrm{SiC}$ coating from a $\mathrm{UO}_{2}-\mathrm{Ag}$ particle after annealing for $2000 \mathrm{~h}$ at $1450^{\circ} \mathrm{C}$ in a thermal gradient of $275^{\circ} \mathrm{C} / \mathrm{cm}$. Note the similarity to the as-deposited structure. No second phases or grain boundary films are observed in this coating. Analysis by EDX detected a large concentration of Ag accumulating at the inner surface of the SiC, sut no $\mathrm{Ag}$ was detected along several grain boundaries probed with a 100- $\AA$ spot. The kinetics of Ag transport through SiC suggest a grain boundary mechanism. ${ }^{2}$ Our results suggest that, if a grain boundary layer

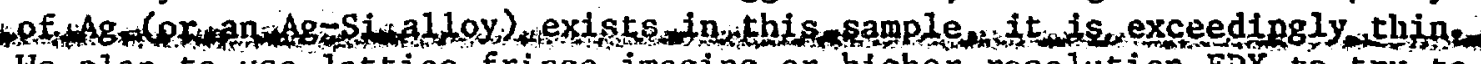
We plan to use lattice fringe imaging or higher resolution EoX to try to resolve this layer.

Acknowledgment: R. L. Pearson provided the $\mathrm{UC}_{2}$-ifo-Ru-Rh-Pd particles and performed the theraal gradient annealing. Research sponsored by the High-Temperature Reactor Progran, U.S. Department of Energy, under contract W-7405-eng-26, with the Union Carbide Corporation.

IT. B. Lindemer and R. L. Pearson, J.Am. Cer. Soc. 60(1-2): 5-17 (1977). 2H. Nabielek, P. E. Brown, and P. Offermann, Nuct. Tecinot. 35: 483-93 (1977). 

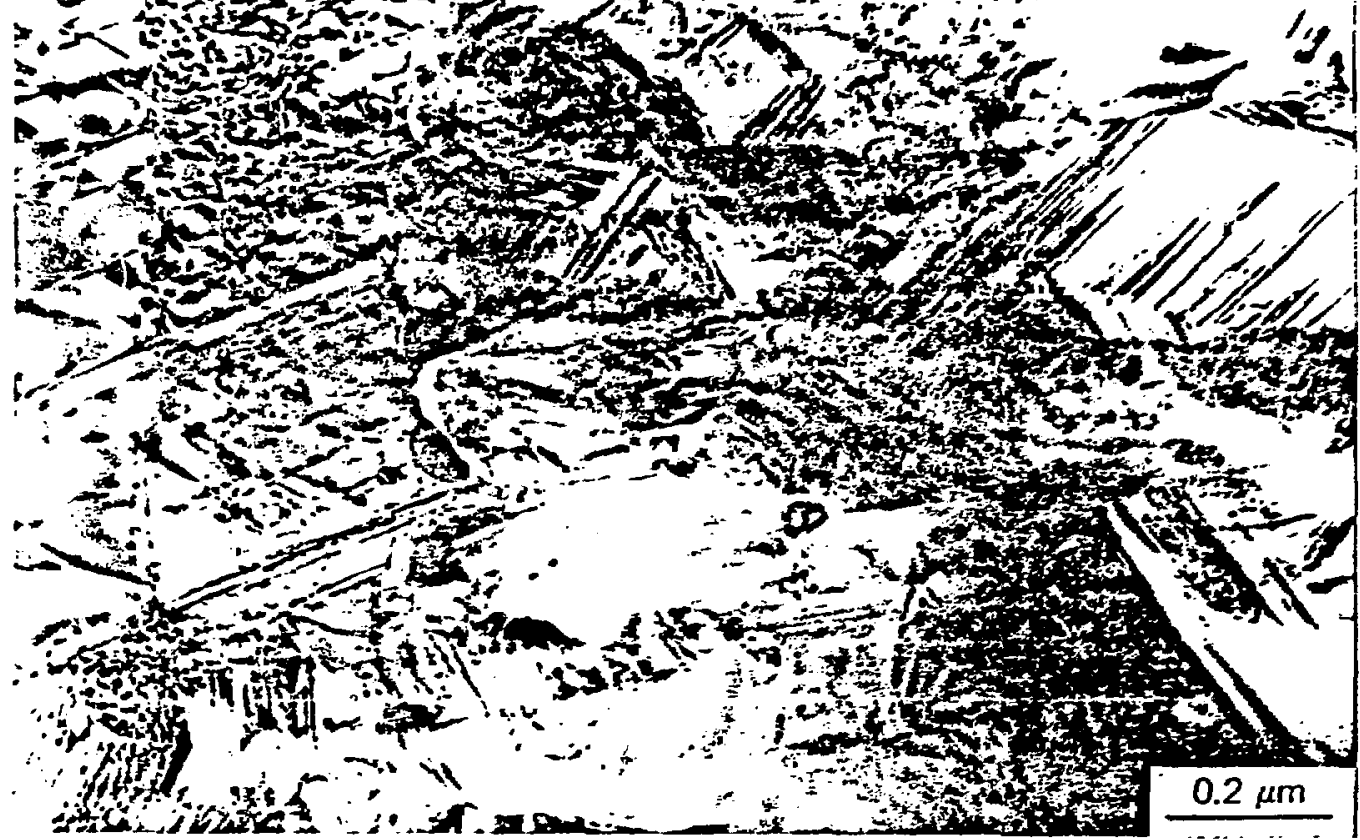

Fig. 1. Pyrolytic SiC as deposited. Growti direction is right to left.

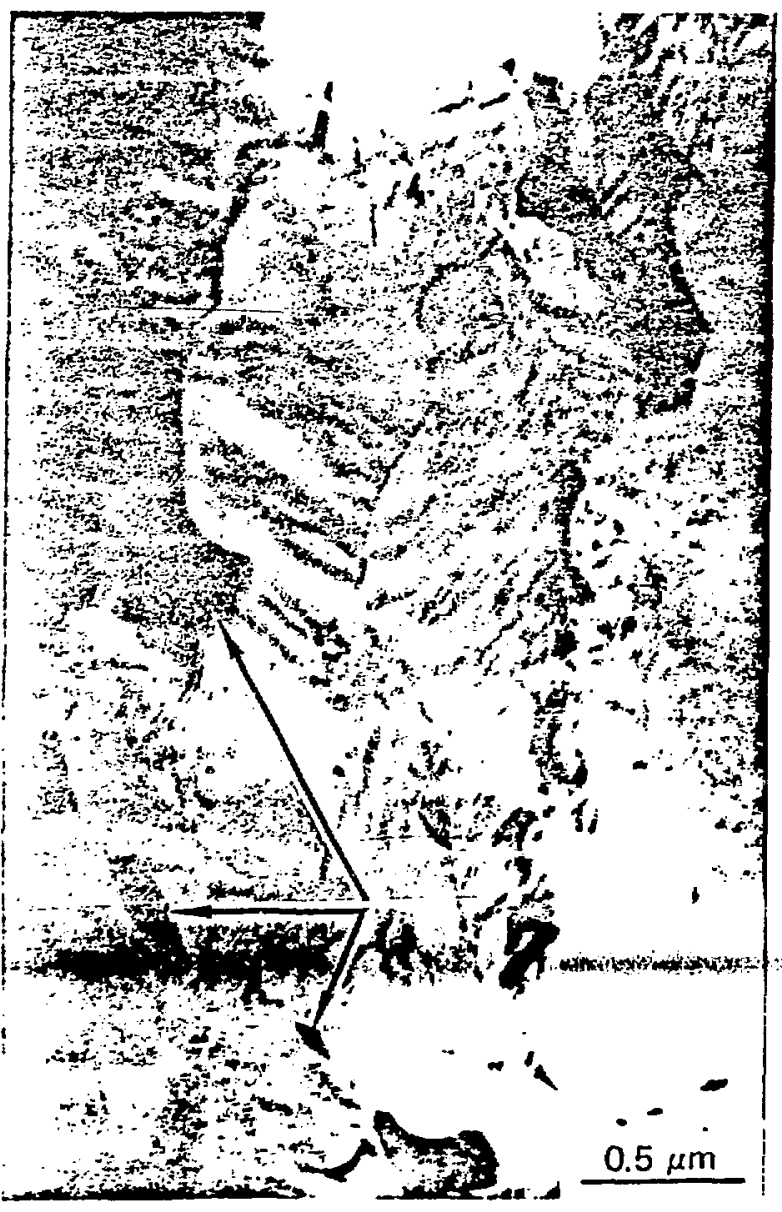

Fig. 2. Nodules of Pd-Rh-Si alloy at SiC grain boundaries after annealing $\mathrm{UC}_{2}-\mathrm{Mo}-\mathrm{Rh}-\mathrm{Ru}-\mathrm{Pd}$ particle.

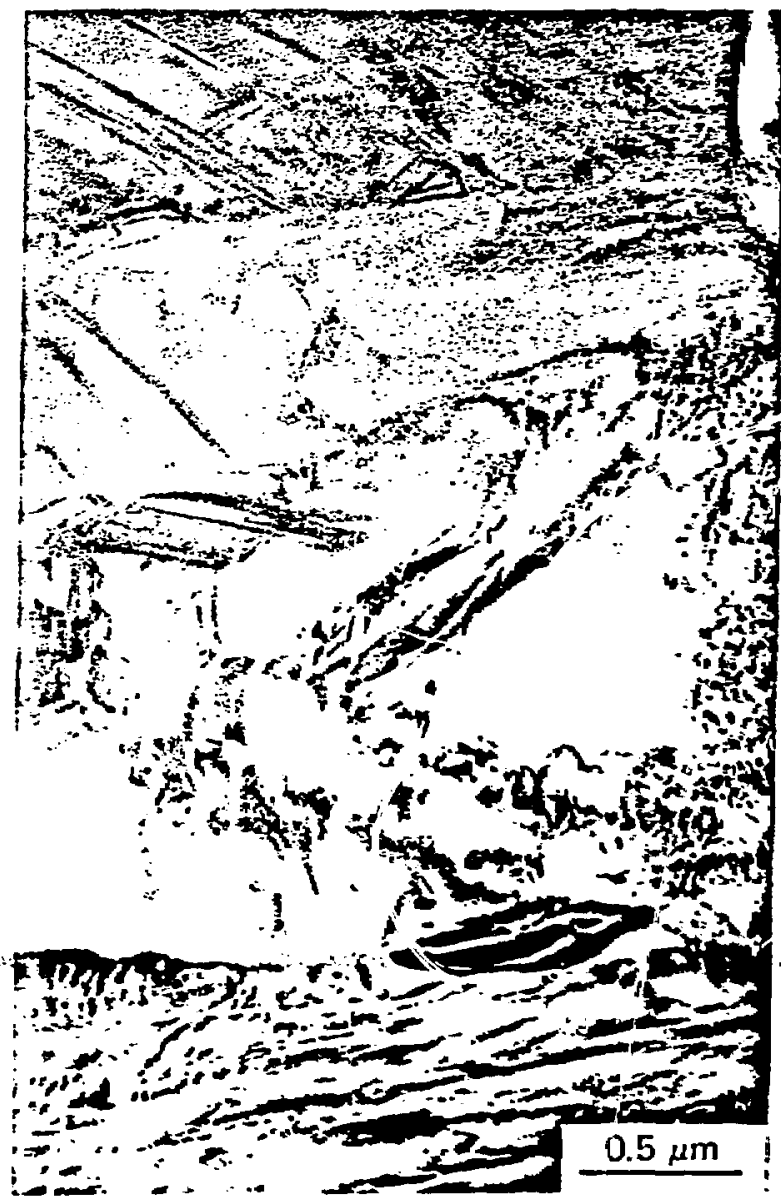

Fig. 3. SiC coating on $\mathrm{Ag}$-doped $\mathrm{UO}_{2}$ particle after annealing. 